\title{
Reverse transcription-quantitative polymerase chain reaction: description of a RIN-based algorithm for accurate data normalization
}

\author{
Alexandre Ho-Pun-Cheung ${ }^{1,2,3}$, Caroline Bascoul-Mollevi ${ }^{4}$, Eric Assenat ${ }^{1,5}$, \\ Florence Boissière-Michot ${ }^{6}$, Frédéric Bibeau ${ }^{6}$, Dominic Cellier ${ }^{2}$, \\ Marc Ychou ${ }^{1,5}$ and Evelyne Lopez-Crapez*3
}

Address: ${ }^{1}$ INSERM U896, Val d'Aurelle Cancer Institute, Montpellier, France, ${ }^{2}$ Merck Serono, Lyon, France, ${ }^{3}$ Department of Oncobiology, Val d'Aurelle Cancer Institute, Montpellier, France, ${ }^{4}$ Department of Biostatistics, Val d'Aurelle Cancer Institute, Montpellier, France, ${ }^{5}$ Department of Medical and Digestive Oncology, Val d'Aurelle Cancer Institute, Montpellier, France and ${ }^{6}$ Department of Pathology, Val d'Aurelle Cancer Institute, Montpellier, France

E-mail: Alexandre Ho-Pun-Cheung - alex.hpc@valdorel.fnclcc.fr; Caroline Bascoul-Mollevi - Caroline.Mollevi@valdorel.fnclcc.fr; Eric Assenat - eric.assenat@valdorel.fnclcc.fr; Florence Boissière-Michot - fboissiere@valdorel.fnclcc.fr;

Frédéric Bibeau - bibeau@valdorel.fnclcc.fr; Dominic Cellier - dominic.cellier@merck.fr; Marc Ychou - mychou@valdorel.fnclcc.fr; Evelyne Lopez-Crapez* - ecrapez@valdorel.fnclcc.fr

${ }^{*}$ Corresponding author

Published: 15 April 2009

BMC Molecular Biology 2009, 10:31 doi: 10.1186/147|-2199-10-31

This article is available from: http://www.biomedcentral.com/|47|-2/99//0/3।

(c) 2009 Ho-Pun-Cheung et al; licensee BioMed Central Ltd.

This is an Open Access article distributed under the terms of the Creative Commons Attribution License (http://creativecommons.org/licenses/by/2.0), which permits unrestricted use, distribution, and reproduction in any medium, provided the original work is properly cited.

\footnotetext{
Abstract

Background: Reverse transcription-quantitative polymerase chain reaction ( $R T-q P C R$ ) is the gold standard technique for mRNA quantification, but appropriate normalization is required to obtain reliable data. Normalization to accurately quantitated RNA has been proposed as the most reliable method for in vivo biopsies. However, this approach does not correct differences in RNA integrity.

Results: In this study, we evaluated the effect of RNA degradation on the quantification of the relative expression of nine genes (I 8S, ACTB, ATUB, B2M, GAPDH, HPRT, POLR2L, PSMB6 and RPLPO) that cover a wide expression spectrum. Our results show that RNA degradation could introduce up to $100 \%$ error in gene expression measurements when RT-qPCR data were normalized to total RNA. To achieve greater resolution of small differences in transcript levels in degraded samples, we improved this normalization method by developing a corrective algorithm that compensates for the loss of RNA integrity. This approach allowed us to achieve higher accuracy, since the average error for quantitative measurements was reduced to $8 \%$. Finally, we applied our normalization strategy to the quantification of EGFR, HER2 and HER3 in 104 rectal cancer biopsies. Taken together, our data show that normalization of gene expression measurements by taking into account also RNA degradation allows much more reliable sample comparison.

Conclusion: We developed a new normalization method of RT-qPCR data that compensates for loss of RNA integrity and therefore allows accurate gene expression quantification in human biopsies.
} 


\section{Background}

Reverse transcription-quantitative polymerase chain reaction (RT-qPCR) is the most sensitive method for mRNA quantification [1-4] as it allows the detection of rare transcripts and the observation of small variations in gene expression. Quantification of mRNA by RT-qPCR can be either absolute or relative. Absolute quantification gives the precise copy number of a target mRNA, but requires the construction of a calibration curve using standards of known concentration. On the other hand, relative quantification expresses the target quantity for an experimental sample as an $\mathrm{n}$-fold difference relative to a calibrator. This is the method of choice to compare changes in mRNA expression between different samples. However, it requires data normalization in order to obtain biologically relevant results [5]. Generally this involves the use of one or several housekeeping genes, whose expression is assumed to be stable between individuals, experimental conditions or physiological states.

In molecular oncology, pre-therapeutic biopsies are interesting material for gene expression studies that aim at identifying prognostic or predictive molecular markers. However, it has been suggested that housekeeping genes should not be used for normalization when studies involve biopsies, since they exhibit large expression variability between individuals [6]. As an alternative, normalization to accurately quantitated total RNA has been proposed [4] and then validated in breast cancer biopsies [6]. This method relies on the precise measurement of the template RNA concentration $[6,7]$ in order to ensure that equal amounts of RNA are used for reverse transcription (RT). Nevertheless, this may not be sufficient to allow reliable comparison among samples. Indeed, variations in the template RNA quality can introduce significant differences in subsequent RT-qPCR results [8]. RNA quality encompasses both its purity (absence of inhibitors) and its integrity (absence of degradation). Variability is mostly related to RNA integrity, as its degradation may greatly affect the measured gene expression levels $[8,9]$. Besides, previous studies suggested that there is a linear relation between gene expression measurement and RNA degradation [10-12]. However, to date, RNA integrity has not been taken into account for normalization of gene expression to total RNA.

The aim of this work was to evaluate the limits of normalization to accurately quantitated total RNA when using degraded samples and to improve this method by introducing a normalization factor that compensates for the loss of RNA integrity. For this purpose, using cell lines we first assessed the influence of RNA degradation on the quantification of the relative expression of nine genes (18S, ACTB, ATUB, B2M, GAPDH, HPRT, POLR2L, $P S M B 6$ and RPLPO) that cover a wide expression spectrum. Our results show that RNA degradation could introduce large errors in gene expression measurements when data were normalized to total RNA. Therefore, to avoid unspecific variations due to RNA degradation, we developed a corrective algorithm that take into account the RNA integrity of each sample and we validated the proposed model through the quantification of EGFR, HER2 and HER3 mRNA in colon and breast cancer cell lines. Finally, we applied this strategy for the quantification of EGFR, HER2 and HER3 in rectal cancer biopsies.

\section{Results \\ Quality Control of the RT-qPCR assay}

We accurately measured the RNA concentration of the cell line samples using a tray cell system combined to a SAFAS UV mc2 spectrophotometer, and we verified sample purity by determining the $\mathrm{A}_{260} / \mathrm{A}_{280}$ ratio, which was always comprised between 2.0 and 2.1.

To assess sample-to-sample variations in the efficiency of both RT and PCR steps, we added a definite amount of an exogenous plant mRNA control (CAB mRNA, Table 1) to the RT reaction mix. After CDNA synthesis and amplification by qPCR, CAB expression was detected within a 1.5 -fold range of concentration in all cell line samples. This suggests that there was no significant difference in the efficiency of both RT and PCR steps between samples.

\section{Effect of RNA degradation on relative gene expression}

To evaluate the limits of normalization to total RNA when using samples with impaired RNA integrity, we studied the effect of RNA degradation on gene relative expression. For that purpose, we aliquoted intact total RNA from HCT116, BxPC-3 and A427 cell lines and we gradually degraded each aliquot by hydrolysis at $70^{\circ} \mathrm{C}$ for different length of time ranging between 0 and 165 min. We monitored the degree of degradation with an Agilent 2100 bioanalyzer following the RNA integrity number (RIN) classification [13]. For each cell line, we obtained increasingly degraded samples, with RIN values going from 10 to 4.7. Figure 1 illustrates this artificial degradation by presenting the different degraded RNA samples obtained for the HCT116 cell line. Subsequently, using the artificially degraded RNA samples, we correlated the RIN of the input RNA with the relative transcription level of 9 target genes (Table 1: Target genes - training set), expressed as an n-fold difference relative to the intact (RIN $=10$ ) samples. For all the studied genes and whatever the cell line considered, we found a linear relation between the RIN and the 
Table I: Genes examined

\begin{tabular}{|c|c|c|c|c|c|}
\hline Gene symbol & Gene name & $\begin{array}{c}\text { GenBank } \\
\text { accession no. }\end{array}$ & Primer sequences $\left(5^{\prime} \rightarrow 3^{\prime}\right)$ & $\begin{array}{l}\text { Amplicon } \\
\text { size (bp) }\end{array}$ & $\begin{array}{c}\text { qPCR } \\
\text { efficiency (\%) }\end{array}$ \\
\hline \multicolumn{6}{|c|}{ Control gene (assessment of RT-qPCR inhibitors) } \\
\hline$C A B$ & $\begin{array}{l}\text { A. thaliana chlorophyll a/b- } \\
\text { binding protein }\end{array}$ & $\times 56062$ & $\begin{array}{l}\text { F: CCATTGCATTTGTTGAGCAC } \\
\text { R: CAATTCCTCGAGCTTCTTGG }\end{array}$ & 119 & 100 \\
\hline \multicolumn{6}{|c|}{ Target genes - training set } \\
\hline 185 & I8S ribosomal RNA & X03205 & $\begin{array}{l}\text { F: GGCGCCCCCTCGATGCTCTTAG } \\
\text { R: } \\
\text { GCTCGGGCCTGCTTTGAACACTCT }\end{array}$ & 89 & 98 \\
\hline ACTB & Beta-actin & NM_00IIOI & $\begin{array}{l}\text { F: CTGTGGCATCCACGAAACTA } \\
\text { R: AGTACTTGCGCTCAGGAGGA }\end{array}$ & 200 & 100 \\
\hline ATUB & Alpha tubulin & NM_006082 & $\begin{array}{l}\text { F: TTACCTCGACTCTTAGCTTGTCG } \\
\text { R: GGATGGAGATGCACTCACG }\end{array}$ & 107 & 92 \\
\hline$B 2 M$ & Beta-2-microglobulin & NM_004048 & $\begin{array}{l}\text { F: CACCCCCACTGAAAAAGATG } \\
\text { R: } \\
\text { ATATTAAAAAGCAAGCAAGCAGAA }\end{array}$ & 167 & 93 \\
\hline GAPDH & $\begin{array}{l}\text { Glyceraldehyde-3-phosphate } \\
\text { dehydrogenase }\end{array}$ & NM_002046 & $\begin{array}{l}\text { F: TGCACCACCAACTGCTTAGC } \\
\text { R: GGCATGGACTGTGGTCATGAG }\end{array}$ & 87 & 100 \\
\hline HPRT & $\begin{array}{l}\text { Hypoxanthine phosphoribosyl } \\
\text { transferase I }\end{array}$ & NM_000194 & $\mathrm{F}:$ & & \\
\hline
\end{tabular}

Forward and reverse primer sequences are indicated by "F" and "R", respectively.

TGATAGATCCATTCCTATGACTGTAGA

R: AAGACATTCTTTCCAGTTAAAGTTGAG I2694POLR2LPolymerase RNA II polypeptide LNM_02II28F: CAACAAGTGGGAGGCTTACCT

R: AGCTTCTCGATCAGGTCCACI3298PSMB6Proteasome subunit YNM 002798F: GATACCGGGAAGACCTGATG

R: AATGGCAAAGGACTGCCTTAI I699RPLPORibosomal protein, large, P0NM_00I002F: CACTGAGATCAGGGACATGTTG

R: CTTCACATGGGGCAATGG I I 3 100Target genes - validation setEGFREpidermal growth factor receptorNM_005228F:

CTGGATCCCAGAAGGTGAGA

R: GCCATCACGTAGGCTTCATCI I I I 00HER2v-erb-b2 erythroblastic leukemia viral oncogene homolog 2NM_004448F:

CTCCTCCTCGCCCTCTTG

R: AGCATGTCCAGGTGGGTCTI 0790HER3v-erb-b2 erythroblastic leukemia viral oncogene homolog 3NM_001982F:

GTGGACTCGAGCAACATTGA

R: CCGTACTGTCCGGAAGACATI4797Forward and reverse primer sequences are indicated by "F" and "R", respectively.

expression ratio (Figure 2 for the HCT116 cell line) (Table 2). The coefficients of determination $\left(\mathrm{R}^{2}\right)$ ranged between 0.86 and 1.00 . The mean slope value was 0.086 \pm 0.025 (95\% CI 0.076-0.096). The relatively low standard deviation observed indicates that all genes had comparable degradation profiles. Obviously, the lowest expression ratios were obtained for the most degraded samples. The minimum ratio observed was 0.48 for the RPLP0 gene in the HCT116 sample with RIN $=4.7$ and it corresponded to a 2.08-fold difference between the intact sample ratio and the measured expression ratio. In other words, there was an error of $108 \%$ in the reported expression level of RPLP0 in this sample. Similarly, the maximum errors observed for samples with $5 \leq$ RIN $<6,6 \leq$ RIN $<7,7 \leq$ RIN $<8$ and RIN $\geq 8$ reached $104 \%, 92 \%, 75 \%$ and $47 \%$, respectively.

\section{Normalization of RNA degradation-related variations using a RIN-based algorithm}

To set up a normalizing factor that could compensate for the loss of RNA integrity, we first determined the average gene degradation profile based on the data we obtained for 18S, ACTB, ATUB, B2M, GAPDH, HPRT, POLR2L,
PSMBG and RPLPO in the increasingly degraded HCT116, BxPC-3 and A427 RNA samples (Figure 3). We then modeled our data by linear regression analysis of the mean measured ratios such that the average degradation profile followed the relationship $\mathrm{y}=\mathrm{a} \times \mathrm{RIN}+\mathrm{b}$, where $\mathrm{a}=0.08$ and $\mathrm{b}=0.19$. Since each gene's transcription level was expressed as an n-fold difference relative to the RIN = 10 sample of the corresponding cell line, the expected ratio for intact samples (RIN $=10)$ corresponded to the line $y=1$. The RIN-normalized ratio $\left(R_{R I N}\right)$ could then be calculated as follow:

$$
\mathrm{R}_{\mathrm{RIN}}=\text { Measured ratio }+(\text { Measured ratio } \times(1-\mathrm{y}) / \mathrm{y})
$$

To assess the validity of this normalization factor, we applied our model to the quantification of EGFR, HER2 and HER3 expression in LS174T (colon adenocarcinoma) and SKBr3 (breast carcinoma) samples displaying variable RNA integrity (Table 3 ). For each measure, the accuracy was greatly increased when using the corrective factor. While pre-normalized data exhibited errors up to $100 \%$ in gene quantification, the maximum error after normalization was below $25 \%$. The mean error for the normalized ratios was $8.4 \% \pm 6.6(95 \%$ CI $5.6-11.2)$. 

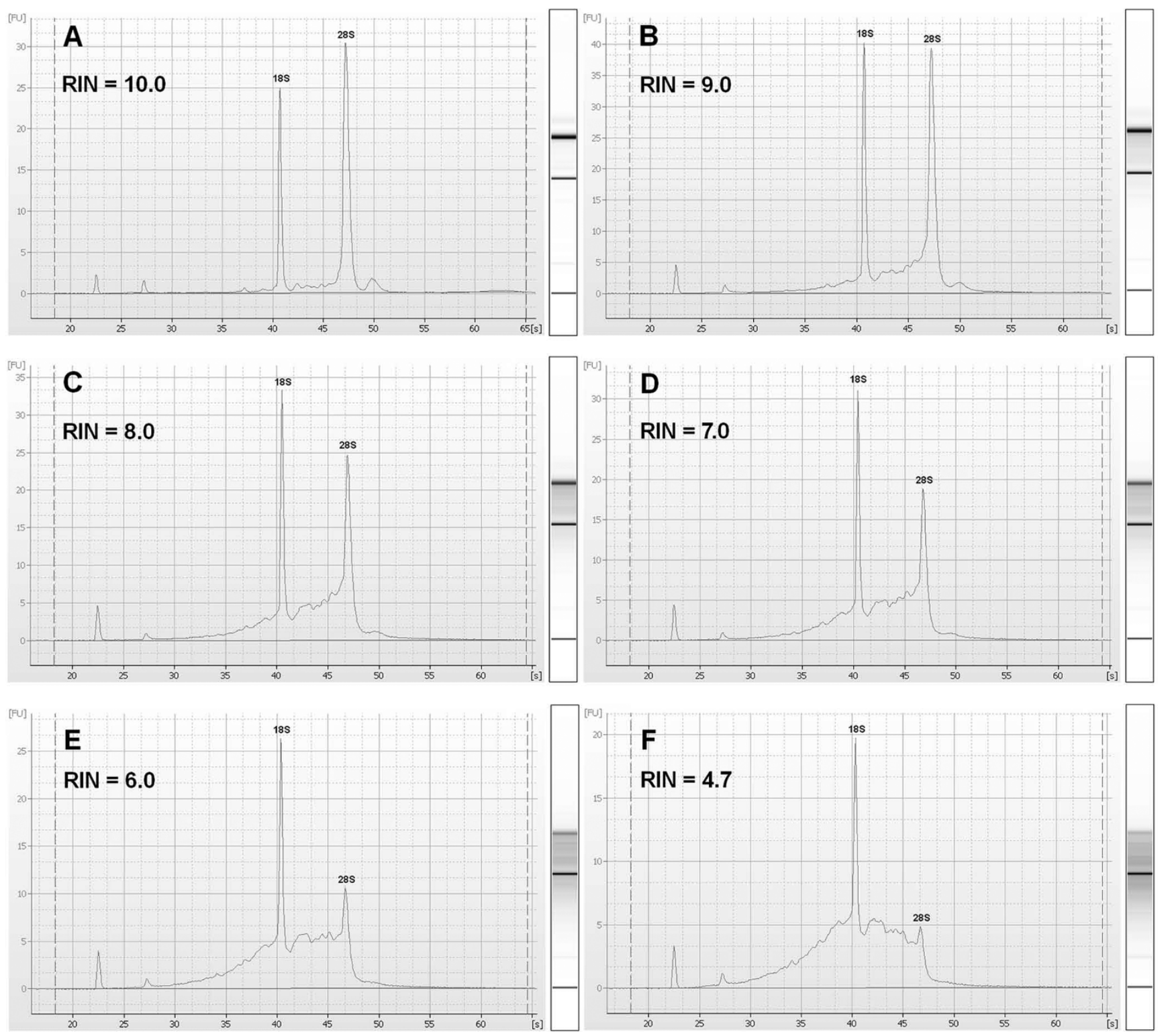

\section{Figure I}

Artificial degradation of HCTII 6 total RNA. Several aliquots of a single HCTII6 total RNA preparation were degraded at $70^{\circ} \mathrm{C}$ for different length of time and analyzed by the Agilent 2100 bioanalyzer. The resulting electrophoregrams and RIN after $0,30,5 \mathrm{I}, 75,140$ and 165 minutes of incubation are shown in panel A, B, C, D, E and F, respectively.

\section{Application of the RIN-based normalization factor in mRNA quantification of biopsy samples}

To evaluate the accuracy of normalization to total RNA of RT-qPCR data obtained from in vivo biopsies, we determined the RIN of 112 RNA samples isolated from 56 paired normal/tumor rectal tissues (Figure 4). The majority $(73.2 \%)$ of samples were distributed in the $5 \leq$ RIN $<6$ and $6 \leq$ RIN $<7$ categories. One hundred and four RNA samples had sufficient RNA concentration for RT, and cDNA were obtained for these samples. Then, we compared the relative expression of EGFR, HER2 and HER3 in these samples (Figure 5 for EGFR) with and without the application of our RIN-based normalization factor. The mean fold-difference between non-normalized and RINnormalized values was $1.52 \pm 0.17$ (95\% CI 1.47-1.55) and ranged from 1.13 to 2.10. Moreover, our RIN-based algorithm allowed the exposure of some differences in gene expression levels among samples that could not have been seen otherwise. For instance, without normalization, sample 48 and 50 exhibited EGFR expression ratios of 4.59 

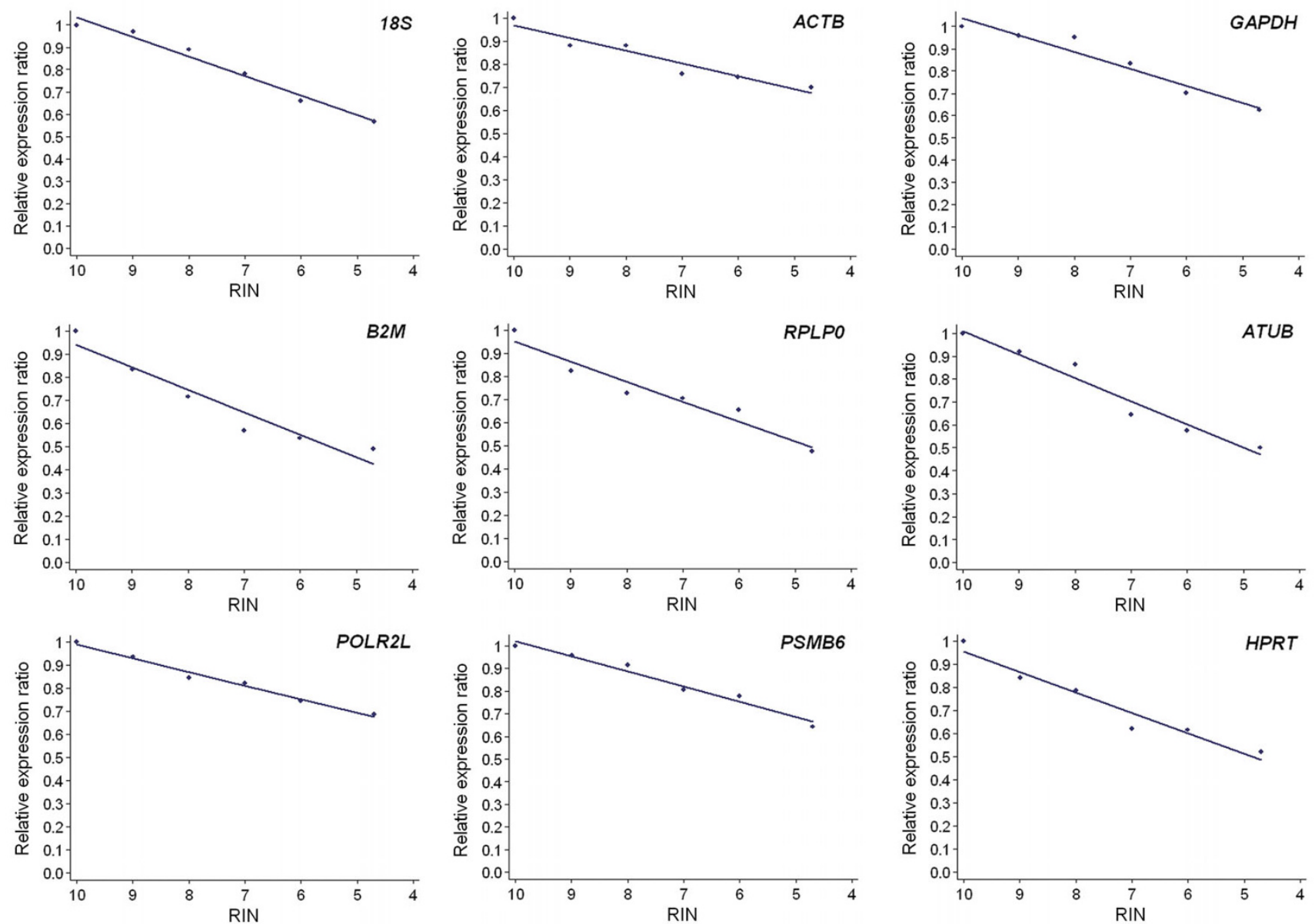

Figure 2

Correlation between gene expression ratio and RIN in the HCT I 6 cell line. The expression measurements of nine genes in increasingly degraded HCTII 6 samples are presented. The relationship between relative expression ratio and RIN was modeled by linear regression analysis.

Table 2: Correlation between RIN and relative gene expression for 9 genes in the HCTII6, BxPC-3 and A427 cell lines

\begin{tabular}{|c|c|c|c|c|c|c|c|c|c|}
\hline \multirow[t]{2}{*}{ Gene } & \multicolumn{3}{|c|}{ НCTII6 } & \multicolumn{3}{|c|}{ BxPC-3 } & \multicolumn{3}{|c|}{ A427 } \\
\hline & Slope & Intercept & $\mathbf{R}^{2}$ & Slope & Intercept & $\mathbf{R}^{2}$ & Slope & Intercept & $\mathbf{R}^{2}$ \\
\hline 185 & 0.09 & 0.16 & 0.98 & 0.14 & -0.41 & 1.00 & 0.11 & -0.16 & 0.94 \\
\hline ACTB & 0.06 & 0.42 & 0.92 & 0.10 & -0.03 & 0.94 & 0.06 & 0.41 & 0.99 \\
\hline ATUB & 0.10 & -0.01 & 0.96 & 0.14 & -0.41 & 0.99 & 0.10 & -0.01 & 0.95 \\
\hline$B 2 M$ & 0.10 & -0.03 & 0.92 & 0.10 & 0.03 & 0.92 & 0.07 & 0.34 & 0.92 \\
\hline GAPDH & 0.08 & 0.27 & 0.94 & 0.10 & 0.02 & 0.98 & 0.08 & 0.22 & 0.98 \\
\hline HPRT & 0.09 & 0.08 & 0.94 & 0.10 & 0.05 & 0.86 & 0.08 & 0.16 & 0.96 \\
\hline POLR2L & 0.06 & 0.4 & 0.98 & 0.06 & 0.43 & 0.92 & 0.04 & 0.60 & 0.97 \\
\hline PSMB6 & 0.07 & 0.35 & 0.97 & 0.09 & 0.14 & 0.99 & 0.05 & 0.53 & 0.99 \\
\hline RPLPO & 0.09 & 0.09 & 0.94 & 0.11 & -0.07 & 0.99 & 0.06 & 0.33 & 0.97 \\
\hline
\end{tabular}

A regression analysis of the relationship between relative gene expression ratios and RIN was performed such that the expression ratio follows the relationship $y=a \times R I N+b$, a being the slope and $b$ the intercept. The coefficients of determination $\left(R^{2}\right)$ are also presented. 

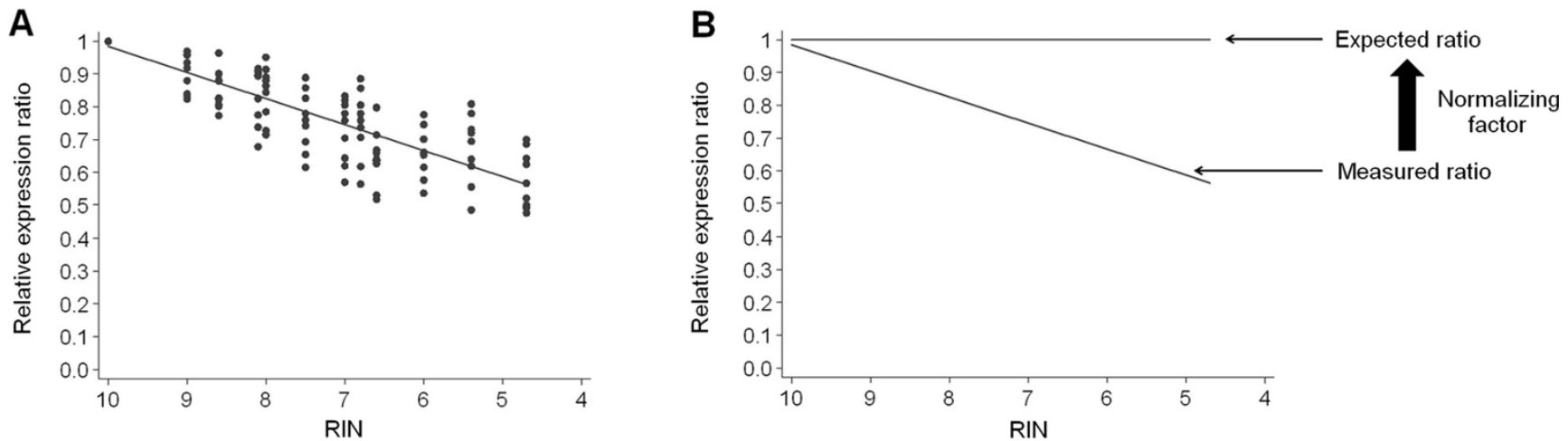

Figure 3

Determination of a RIN-based normalizing factor. (A) The measured expression ratios of 9 genes in HCTI I6, BxPC-3, and A427 samples with decreasing RNA integrity allowed the determination of an average gene degradation profile that follows the equation: relative expression ratio $=0.08 \times \mathrm{RIN}+0.19$. (B) $\mathrm{A}$ RIN-based normalizing factor was determined from the deviation between the average gene degradation and the line $y=I$, which corresponds to the expected ratio for intact samples $(\mathrm{RIN}=10)$.

Table 3: Normalization of EGFR, HER2 and HER3 expression according to the RIN

\begin{tabular}{|c|c|c|c|c|c|c|c|}
\hline \multirow[t]{2}{*}{ Cell line } & \multirow[t]{2}{*}{ RIN } & \multicolumn{2}{|c|}{ EGFR } & \multicolumn{2}{|c|}{ HER2 } & \multicolumn{2}{|c|}{ HER3 } \\
\hline & & $\begin{array}{l}\text { Measured } \\
\text { ratio } \\
\text { (\% error) }\end{array}$ & $\begin{array}{c}\text { RIN-normalized } \\
\text { ratio } \\
\text { (\% error) }\end{array}$ & $\begin{array}{l}\text { Measured } \\
\text { ratio } \\
\text { (\% error) }\end{array}$ & $\begin{array}{c}\text { RIN-normalized } \\
\text { ratio } \\
\text { (\% error) }\end{array}$ & $\begin{array}{l}\text { Measured } \\
\text { ratio } \\
\text { (\% error) }\end{array}$ & $\begin{array}{c}\text { RIN-normalized } \\
\text { ratio } \\
\text { (\% error) }\end{array}$ \\
\hline \multirow[t]{5}{*}{ LSI74T } & 10.0 & $1.00(0.0)$ & - & $1.00(0.0)$ & - & $1.00(0.0)$ & - \\
\hline & 8.0 & $0.75(33.3)$ & $0.91(9.9)$ & $0.76(31.6)$ & $0.93(7.5)$ & $0.83(20.5)$ & $1.01(1.0)$ \\
\hline & 7.1 & $0.63(58.7)$ & $0.84(19.0)$ & $0.74(35.1)$ & $0.99(1.0)$ & 0.63 (58.7) & $0.84(19.0)$ \\
\hline & 6.6 & $0.60(66.7)$ & $0.85(1.6)$ & $0.63(58.7)$ & 0.89 (12.4) & $0.62(6 \mid .3)$ & 0.87 (14.9) \\
\hline & 5.4 & $0.50(100.0)$ & $0.81(23.5)$ & $0.60(66.7)$ & $0.98(2.0)$ & $0.55(81.8)$ & $0.89(12.4)$ \\
\hline \multirow[t]{5}{*}{ SKBr3 } & 10.0 & $1.00(0.0)$ & - & $1.00(0.0)$ & - & $1.00(0.0)$ & - \\
\hline & 7.9 & $0.84(19.0)$ & $1.03(3.0)$ & $0.80(25.0)$ & $0.99(1.0)$ & 0.85 (I7.6) & $1.05(5.0)$ \\
\hline & 7.2 & $0.73(37.0)$ & $0.96(4.2)$ & $0.68(47.0)$ & 0.90 (II.I) & $0.74(35.1)$ & $0.98(2.0)$ \\
\hline & 5.9 & $0.64(56.2)$ & $0.98(2.0)$ & $0.61(63.9)$ & $0.93(7.5)$ & $0.72(38.9)$ & $1.10(10.0)$ \\
\hline & 5.1 & $0.56(78.6)$ & $0.95(5.2)$ & $0.57(75.4)$ & $0.96(4.2)$ & $0.63(58.7)$ & $1.07(7.0)$ \\
\hline
\end{tabular}

EGFR, HER2 and HER3 gene transcription levels were assessed in LSI74T and SKBr3 cell samples with decreasing RNA integrity and expressed as nfold difference relative to the intact (RIN $=10)$ sample. RIN-normalized ratios were calculated according to the following formula: RIN-normalized ratio $=$ Measured ratio $+($ Measured ratio $\times(I-(0.08 \times \mathrm{RIN}+0.19)) /(0.08 \times \mathrm{RIN}+0.19))$. The percent of error $(\%$ error $)$ shows the accuracy of the estimated (i.e. measured or normalized) ratio and was calculated as follow: $\%$ error $=(($ expected ratio - estimated ratio)/estimated ratio $) \times 100 \%$.

and 4.61, respectively, which would lead to the conclusion that EGFR was expressed at similar levels in both samples. After normalization of variations due to RNA degradation using our corrective RIN-based algorithm, EGFR was more strongly expressed in sample 48 (ratio $=9.60$ ) than in sample 50 (ratio $=6.91$ ). Furthermore, variations in RNA integrity may generate misleading differences in gene expression measurements. Indeed, the non-normalized ratios of sample 95 (ratio $=7.71$ ) and sample 100 (ratio = 9.07) suggested that the former exhibited a lower EGFR expression level, while the RIN-normalized ratios led to the opposite conclusion. EGFR expression was actually higher in sample 95 (ratio $=15.10)$ than in sample $100($ ratio $=11.51)$.

\section{Discussion}

Normalization of gene expression levels to total RNA requires precise quantification of the RNA template. Several methods exist for measuring RNA concentrations, and we have previously discussed their respective advantages and drawbacks [14]. In this study, we determined total RNA concentration by measuring the optical density at $260 \mathrm{~nm}$ with a TrayCell system associated to a SAFAS UV mc2 spectrophotometer. This system offers sensitivity down to $2 \mathrm{ng} / \mu \mathrm{l}$ and allows the analysis of extremely small volumes (0.7-4 $\mu \mathrm{l})$, which has the advantage of avoiding dilution errors. Once the sample concentration is accurately determined, the simplest way to normalize gene expression using total 


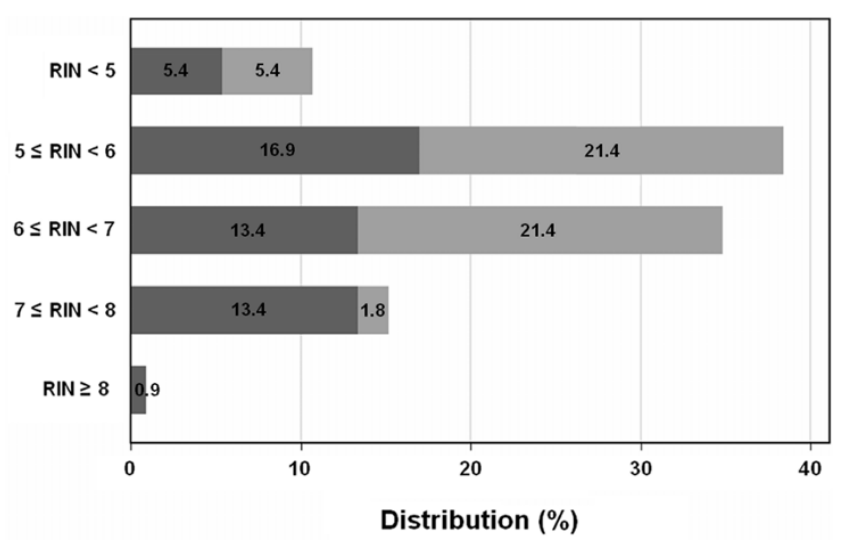

Figure 4

RIN value frequency distribution for RNA isolated from I I 2 rectal biopsies. Dark and light bars correspond to tumor and normal samples, respectively.

RNA is to ensure that equal amounts of input RNA are used for the RT reaction, all the more so that the cDNA yield is dependent on template abundance $[5,15]$.

Normalization to total RNA also requires assessment of the presence of RT-qPCR inhibitors in samples $[6,14]$. These inhibitors, which may include reagents used during RNA isolation, or co-purified biological components $[16,17]$, can reduce the efficiency of both RT and PCR and generate errors in the quantification results. In this study, we used an exogenous $C A B$ mRNA control $[18,19]$ that was co-reverse-transcribed with each sample RNA and then amplified by qPCR. Thus, any variation in $C A B$ expression level would reflect variations in the efficiency of the RT and/or PCR steps. CAB showed a 1.5fold variation range in our cell line cDNA samples, which is comparable to or even narrower than previously reported values for similar exogenous controls $[6,19,20]$. We conclude that in our samples and under our optimized RT-qPCR conditions, there was only a negligible effect of inhibitors on the RT and PCR efficiencies.

Bustin et al. [7] recommended normalization to accurately quantitated total RNA as the least unreliable method, and Tricarico et al. [6] validated it for breast biopsies [6]. However, little was known at that time about the accuracy of this approach when using degraded RNA samples. In this study, we assessed the effect of RNA degradation on the relative gene expression level measured by RT-qPCR in 3 different models, namely colorectal carcinoma (HCT116), pancreatic adenocarcinoma (BxPC-3) and lung adenocarcinoma (A427) cell lines. Different methods to degrade RNA have been described in the literature, including the use of

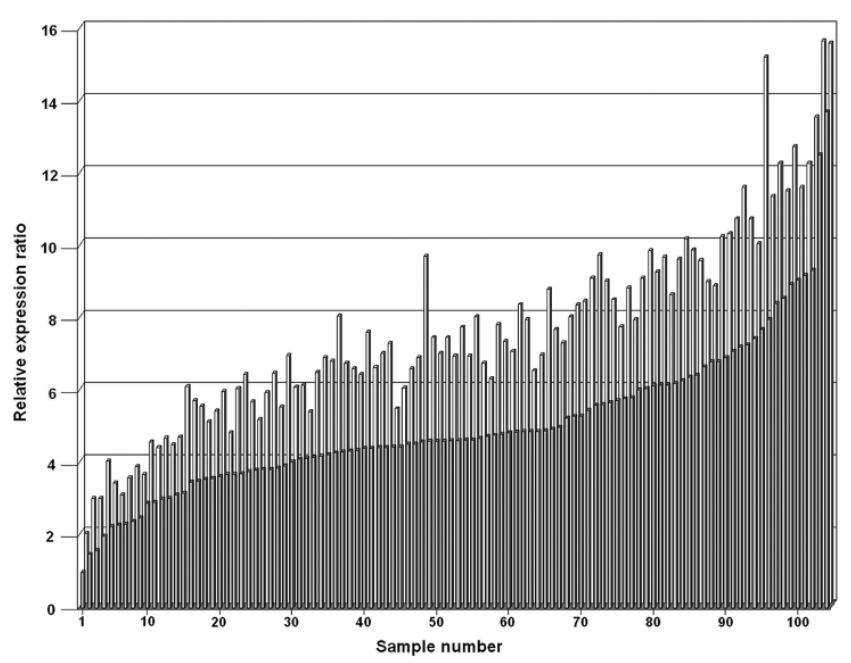

Figure 5

Application of the RIN-based normalization factor for EGFR quantification in rectal biopsy samples. The relative expression ratio corresponds to EGFR expression level, expressed as an $n$-fold difference relative to the sample with the lowest EGFR expression. Dark and light gray bars correspond to non-normalized and RIN-normalized relative expression ratios, respectively.

RNase treatment [11], UV radiation [11], or thermal hydrolysis [21]. While these procedures are artificial and may differ from the natural degradation that occurs during sample handling, they allow producing a collection of RNA samples that are representative of all possible degrees of RNA degradation. Using thermal hydrolysis, we degraded total RNA isolated from HCT116, BxPC-3 and A427 cell lines. We thus obtained samples with decreasing integrity, with RIN values ranging from 10 (intact RNA) to 4.7 (highly degraded RNA), which corresponded to the range allowing reliable RT-qPCR quantification analysis [11]. Then, we measured the expression of 18S, ACTB, ATUB, B2M, GAPDH, HPRT, POLR2L, PSMBG and RPLPO, a group of genes that covers a wide expression range. Since all samples from a given cell line had the same transcriptome, the decrease in the measured gene expression ratios accurately reflected the effect of RNA degradation. Our data demonstrate that there is a linear correlation between the relative expression ratio of a gene and the RIN: the lower the RIN, the higher the decrease in the measured expression level. One should keep in mind that these results may be specific to the protocol used in this study. We have carefully designed our protocol in order to reduce the effects of RNA degradation and maximize the yield of the RT reaction. Specifically, we preferred random hexamers over oligo(dT) or specific primers, which are not appropriate for fragmented RNA [8], and 
we chose PCR product sizes smaller than 200 bp (Table 1), as short amplicons have been shown to be less dependent on RNA integrity [10]. Fleige et al. [11] have already tested the effect of artificial RNA degradation on gene expression for a limited number of genes $(18 S, 28 S$, ACTB and $I L-1 \beta)$ in a large panel of human tissue-derived RNAs. Similarly to our results, they found a linear correlation between gene expression and RIN. However, in their study, this was not true for all tissue types. This may be imputed to differences between our experimental protocols. Specifically, they performed one-step RT-qPCR assays with specific primers, and chose longer PCR products (i.e., 198-338 pb). Tissues definitely show different sensitivity to RNA degradation, but for a givengene that is similarly expressed in two different tissues, the quantification of its expression using an optimized RT-qPCR protocol should be influenced only by the sample's degradation level (i.e. its RIN value), and not by the tissue type.

In our experiment, the most degraded samples exhibited up to 2-fold decrease in gene expression levels. This demonstrates that, for samples with RIN values down to 4.7, variations in RNA integrity may generate an error of approximately $100 \%$ in gene quantification. To address this issue, we asked whether it was possible to determine a RIN-based algorithm that normalizes the loss of RNA integrity in gene quantification. This implies the determination of the gene of interest's degradation profile. Since 1) it is hardly conceivable to model all possible degradation profiles in the short term and 2) the 9 training genes analyzed in this study showed similar degradation profiles, we chose to determine an average degradation profile based on the data we obtained for these genes in colon, pancreatic and lung cancer cells. Then, using this consensus profile, we calculated a normalizing factor that adjusted the RINdependent quantitative measure to the expected value for intact samples.

To assess the validity of this corrective algorithm, we applied the proposed normalization method to the quantification of EGFR, HER2 and HER3 in samples with decreasing RNA integrity obtained from two model-independent cancer cell lines (LS174T, colon; SKBr3, breast). Our results demonstrate that the developed approach greatly reduces RNA degradation-related variations for all genes in each sample. The use of the RIN-corrective algorithm lowered the maximum error in quantification from $100 \%$ to less than $25 \%$, and an average error of less than $10 \%$ was obtained. Such accuracy is desirable, since minimal changes in gene expression levels can have important functional [22] or clinical [23] consequences.

For studies involving human biopsies, analysis of samples with variable RNA integrity is unavoidable as
RNA is usually degraded during sample handling. Therefore, normalization of variations due to RNA degradation is of critical importance. In this study, we assessed the degradation level of 112 RNA extracted from 56 matching normal and tumor rectal biopsies pairs. Nearly $75 \%$ of samples showed RIN values comprised between 5 and 7 and our experiment with gradually degraded cell lines demonstrated that samples within this range of RIN could exhibit important errors in gene expression measurements. To assess the benefit of our RIN-based corrective algorithm, we measured the expression of EGFR, HER2 and HER3 in 104 of the 112 RNAs derived from biopsies and compared non-normalized and RIN-normalized ratios. Our data indicate that, without normalization, differences in sample RNA integrity could generate artificial up- or down-regulations that could lead to misleading interpretation of the results. Although our model will not fit perfectly each gene due to possible differences in degradation profiles, it will significantly reduce unspecific variations. Therefore, we recommend the use of our RIN-based corrective algorithm when normalizing gene expression measurements to accurately quantitated RNA. However, this requires the use of our RT protocol and the design of short PCR products $(<200 \mathrm{pb})$. To make this normalization process more user-friendly, we plan to develop a software program that normalizes target gene expression measurements according to the RIN value in an automatic manner.

\section{Conclusion}

The precision and accuracy of gene expression measurements with RT-qPCR depend on the method used to normalize the data. In this study, we demonstrate that the use of total RNA for RT-qPCR normalization is limited when small differences in gene expression need to be detected. To achieve higher accuracy in RT-qPCR measurements, we improved this method by introducing a RIN-based corrective algorithm. This strategy should correct variations related to RNA degradation and allow accurate gene expression quantitation.

\section{Methods}

\section{Patients' tissues and cell line}

The human cancer cell lines HCT116, BxPC-3, A427, SKBr3 and LS174T were purchased from the American Type Culture Collection and cultured under standard conditions. Cells were harvested at 50\% confluence, washed with phosphate buffered saline, and subsequently used for RNA extraction.

Fifty-six rectal cancer patients were included in this study between January 2006 and February 2008. For all patients, pre-therapeutic biopsies from paired normal/ 
tumor rectal tissues were obtained by endoscopy. Biopsies were frozen at $-80^{\circ} \mathrm{C}$ within 45 minutes and stored under this condition until extraction. The protocol was approved by the CPP of Saint-Eloi Hospital (Montpellier, France), a French Ethic committee for the protection of patients involved in biomedical research.

\section{RNA Isolation and Characterization}

Total RNA was isolated using the RNeasy Mini Kit (Qiagen, Courtaboeuf, France) following the manufacturer's instructions. The extraction included a digestion step with DNase I to prevent subsequent amplification of genomic DNA. Total RNA concentration was determined by measuring the absorbance at $260 \mathrm{~nm}\left(\mathrm{~A}_{260}\right)$ with the SAFAS UV mc2 spectrophotometer (Safas, Monaco, Monaco), using a TrayCell system (Hellma, Paris, France). Total RNA purity was verified by determining the $A_{260} / A_{280}$ ratio. RNA integrity was assessed by microcapillary electrophoresis with the RNA 6000 Nano LabChip kit (Agilent Biotechnologies, Massy, France) and the Agilent 2100 bioanalyzer (Agilent Biotechnologies), which assigns a RIN to each RNA electropherogram. This number ranges from 1 (completely degraded RNA sample) to 10 (intact RNA sample).

\section{Reverse transcription}

For each sample, a 13- $\mu \mathrm{l}$ mix containing $1 \mu \mathrm{g}$ total RNA, $150 \mathrm{ng}$ of random hexamers (Promega, Charbonnieres, France), $1 \mu \mathrm{l}$ of a $10 \mathrm{mM}$ dNTP Mix (Invitrogen, Cergy Pontoise, France), and $0,3 \mathrm{pg}$ of an exogenous plant mRNA spike (A. thaliana chlorophyll a/b-binding protein, $\mathrm{CAB}$ ) (Stratagene, Amsterdam, The Netherlands) was heated at $65^{\circ} \mathrm{C}$ for 5 minutes. After cooling on ice, a $7 \mu$ l-reaction mix containing $1 \mu$ of SuperScript ${ }^{\mathrm{TM}}$ III Reverse Transcriptase (200 U/ $\mu$ l) (Invitrogen), $4 \mu \mathrm{l}$ of $5 \times$ First-Strand Buffer (Invitrogen), $1 \mu$ l of $0.1 \mathrm{M}$ DTT (Invitrogen), and $1 \mu \mathrm{l}$ of SUPERase. $\mathrm{In}^{\mathrm{TM}}(20 \mathrm{U} / \mu \mathrm{l})$ (Ambion, Huntingdon, UK) was added. Then reverse transcription was performed in an Eppendorf ${ }^{\circledR}$ Mastercycler (Eppendorf, Le Pecq, France) with an initial priming step at $25^{\circ} \mathrm{C}$ for 5 minutes, followed by cDNA synthesis at $50^{\circ} \mathrm{C}$ for 60 minutes. A final inactivation step at $70^{\circ} \mathrm{C}$ for 15 minutes completed the reaction.

\section{Quantitative real-time RT-PCR analysis}

We developed quantitative SYBR green PCR assays for the 12 genes involved in this study and the spiked plant mRNA control (Table 1). Real-time PCR amplification was performed in a Rotor-Gene $e^{\mathrm{TM}} 6000$ (Labgene, Archamps, France) using the ABsolute ${ }^{\mathrm{m}}$ Blue QPCR SYBR $^{\circledast}$ Green Mix (ABgene, Courtaboeuf, France). PCR amplification were carried out in a $20-\mu l$ volume with the following cycling conditions: an enzyme activation step at $95{ }^{\circ} \mathrm{C}$ for 15 minutes, followed by 40 cycles consisting of 15 seconds of denaturation at $95^{\circ} \mathrm{C}, 30$ seconds of annealing at $58-64^{\circ} \mathrm{C}$ depending on primers, and 30 seconds of elongation at $72^{\circ} \mathrm{C}$. The specificity of the amplified products was verified by melting curve analysis and agarose gel electrophoresis. For each qPCR run, a standard curve was generated using serial dilutions of a standard cDNA. Amplification efficiencies (E) were calculated from the slope of the standard curves according to the equation: $\mathrm{E}=10[-1 /$ slope $]$, and they ranged from $90 \%$ to $100 \%$. To exclude between-run variations, all cDNA samples were tested in duplicate in the same analytical run along with a calibrator. A value of 1 was attributed to the calibrator and all gene expression levels were expressed as an n-fold difference relative to the calibrator, according to the relative standard curve method [24].

\section{Statistical analysis}

All statistical analyses were performed with the STATA 10.0 software (StataCorp, College Station, TX).

\section{Abbreviations}

qPCR: quantitative polymerase chain reaction; RIN: RNA integrity number; RT: reverse transcription.

\section{Authors' contributions}

$\mathrm{AH}$ designed the study, performed the experiments, and wrote the manuscript. CB performed the statistical analyses and contributed to the content and writing of the paper. EA performed the endoscopic biopsies and provided the clinical samples. FBo and FBi collected and validated the biopsies. DC and MY managed and coordinated the project. EL supervised the design and execution of experiments and participated in the writing of the manuscript. All authors have read and approved the final manuscript.

\section{Acknowledgements}

This work was supported by Merck Santé and the ANRT (Association Nationale de la Recherche Technique).

\section{References}

I. Wang $T$ and Brown MJ: mRNA quantification by real time TaqMan polymerase chain reaction: validation and comparison with RNase protection. Anal Biochem 1999, 269:198-201.

2. Orlando $C$, Pinzani $P$ and Pazzagli M: Developments in quantitative PCR. Clin Chem Lab Med 1998, 36:255-269.

3. Lockey C, Otto E and Long Z: Real-time fluorescence detection of a single DNA molecule. Biotechniques 1998, 24:744-746.

4. Bustin SA: Absolute quantification of mRNA using real-time reverse transcription polymerase chain reaction assays. $J \mathrm{Mol}$ Endocrinol 2000, 25:169-193.

5. Bustin SA, Benes V, Nolan T and Pfaffl MW: Quantitative realtime RT-PCR - a perspective. J Mol Endocrinol 2005, 34:597-60 I.

6. Tricarico C, Pinzani P, Bianchi S, Paglierani M, Distante V, Pazzagli M, Bustin SA and Orlando C: Quantitative real-time reverse transcription polymerase chain reaction: normalization to rRNA or single housekeeping genes is inappropriate for human tissue biopsies. Anal Biochem 2002, 309:293-300. 
7. Bustin SA: Quantification of mRNA using real-time reverse transcription PCR (RT-PCR): trends and problems. J Mol Endocrinol 2002, 29:23-39.

8. Bustin SA and Nolan T: Pitfalls of quantitative real-time reverse-transcription polymerase chain reaction. J Biomol Tech 2004, I5: I55-166.

9. Imbeaud S, Graudens E, Boulanger V, Barlet X, Zaborski P, Eveno E, Mueller $O$, Schroeder A and Auffray C: Towards standardization of RNA quality assessment using user-independent classifiers of microcapillary electrophoresis traces. Nucleic Acids Res 2005, 33:e56.

10. Fleige $S$ and Pfaffl MW: RNA integrity and the effect on the real-time qRT-PCR performance. Mol Aspects Med 2006, 27:126-139.

II. Fleige S, Walf V, Huch S, Prgomet C, Sehm I and Pfaffl MW: Comparison of relative mRNA quantification models and the impact of RNA integrity in quantitative real-time RTPCR. Biotechnol Lett 2006, 28:1601-1613.

12. Auer H, Lyianarachchi S, Newsom D, Klisovic MI, Marcucci G and Kornacker K: Chipping away at the chip bias: RNA degradation in microarray analysis. Nat Genet 2003, 35:292-293.

13. Schroeder A, Mueller O, Stocker S, Salowsky R, Leiber M, Gassmann M, Lightfoot S, Menzel W, Granzow M and Ragg T: The RIN: an RNA integrity number for assigning integrity values to RNA measurements. BMC Mol Biol 2006, 7:3.

14. Ho-Pun-Cheung A, Cellier D and Lopez-Crapez E: [Considerations for normalisation of RT-qPCR in oncology.]. Ann Biol Clin (Paris) 2008, 66:121-129.

15. Karrer EE, Lincoln JE, Hogenhout $S$, Bennett $A B$, Bostock RM, Martineau B, Lucas W], Gilchrist DG and Alexander D: In situ isolation of mRNA from individual plant cells: creation of cell-specific cDNA libraries. Proc Natl Acad Sci USA 1995, 92:38|4-38|8.

16. Freeman WM, Walker SI and Vrana KE: Quantitative RT-PCR: pitfalls and potential. Biotechniques 1999, 26:II2-II5.

17. Nolan T, Hands RE, Ogunkolade $W$ and Bustin SA: SPUD: a quantitative PCR assay for the detection of inhibitors in nucleic acid preparations. Anal Biochem 2006, 35I:308-3I0.

18. Steinau M, Rajeevan MS and Unger ER: DNA and RNA References for qRT-PCR Assays in Exfoliated Cervical Cells. J Mol Diagn 2006, 8: $113-118$.

19. Steinau M, Rajeevan MS, Lee DR, Ruffin MT, Horowitz IR, Flowers LC, Tadros T, Birdsong G, Husain M, Kmak DC, Longton GM, Vernon SD and Unger ER: Evaluation of RNA markers for early detection of cervical neoplasia in exfoliated cervical cells. Cancer Epidemiol Biomarkers Prev 2007, 16:295-301.

20. de Kok JB, Roelofs RW, Giesendorf BA Pennings JL, Waas ET, Feuth T, Swinkels DW and Span PN: Normalization of gene expression measurements in tumor tissues: comparison of I 3 endogenous control genes. Lab lnvest 2005, 85: I54-159.

21. Mueller S: Optimizing real-time quantitative PCR experiments with the Agilent 2100 bioanalyzer. Agilent Technologies Application Note 5989-7730EN 2008.

22. Doebley J and Lukens L: Transcriptional regulators and the evolution of plant form. Plant Cell 1998, 10:1075-1082.

23. Yan H, Dobbie Z, Gruber SB, Markowitz S, Romans K, Giardiello FM, Kinzler KW and Vogelstein B: Small changes in expression affect predisposition to tumorigenesis. Nat Genet 2002, 30:25-26.

24. $A B I$ : Relative quantitation of gene expression. User bulletin No. 2. ABI prism 7700 Sequence Detection System. PE Applied Biosystems.

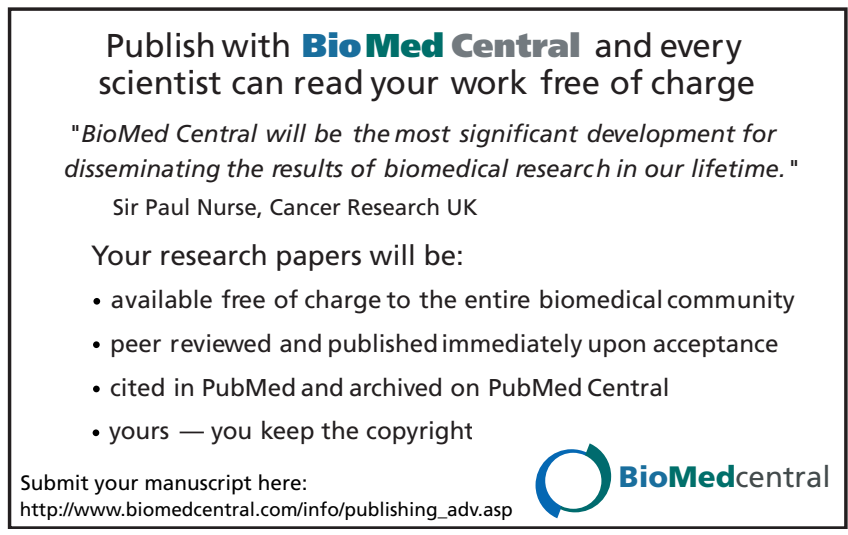

